\title{
O Inframince: A Potencialidade De Um Campo Relacional
}

\section{Leila Reinert}

Doutura, Universidade Anhembi Morumbi / leilareinert@gmail.com

Orcid: 0000-0002-6275-8728 / http://lattes.cnpq.br/6481635538332588

Enviado 30/06/18 / Aceito 05/09/18 


\title{
O Inframince: A Potencialidade De Um Campo Relacional
}

\begin{abstract}
RESUMO
A noção de inframince de Marcel Duchamp fornece um vasto campo de pesquisa. É um terreno fértil para proposições sobre uma estética, uma poética e uma política no campo do design e da arte contemporâneas. Duchamp descreve o inframince enquanto uma qualidade do sensível que se encontra no entre, e é um campo relacional pleno de possibilidades. A experiência sensível reorganiza a existência criando percepções singulares. Este estudo apresenta uma articulação entre a noção de inframince e alguns projetos de design. Considerando os projetos $e$ as qualidades experienciáveis da nossa percepção, este texto propõe uma reflexão sobre como a associação entre inframince e design pode potencializar o processo criativo, nosso ser e estar no mundo.
\end{abstract}

Palavras-chave: Inframince; arte; design. 


\title{
The Infrathin: The Potentiation Of A Relational Field
}

\begin{abstract}
Marcel Duchamp's conception of the infrathin provides a vast field of research. It is a fertile ground for propositions about aesthetics, a poetics and a politics in the field of contemporary design and art. Duchamp describes the infrathin as a quality of the sensitive that is in the between, and it is a relational field full of possibilities. Sensitive experiences reorganize the existence to invent a singular's perception. This study presents an articulation between infrathin's concept and some design's projects. Considering the projects and the qualities of our experienceable perception, this study proposes a reflection on how the association between infrathin and design can leverage our creative processes, our being, and living in the world.
\end{abstract}

Keywords: Infrathin; art; design. 


\section{INTRODUÇÃO}

Design e Arte são campos de ação que instauram regimes de visibilidade e propõem novas dimensões perceptivas a partir de suas produções/ações. São práticas que configuram modos de ver e ser no mundo. No campo ampliado da arte contemporânea, design e arte fazem parte de um mesmo processo e ambos propõem produções e proposições que vão para além dos modos de ver. Agrega-se à construção de estruturas gerais do visível o sensível formas de afetividade.

Para melhor compreensão da questão, recorremos a Marcel Duchamp e as transformações que sua obra e suas proposições propiciaram ao mundo da arte do século $X X$, e que repercutem ainda hoje. Há um aspecto, em especial, dentre as proposições de Duchamp que nos interessa particularmente para articular design e arte: a noção de infra-mince. Duchamp jamais definiu o que seria o inframince, ele somente apresentou operações que poderiam ser denominadas como, ou constatou experiências sensoriais que carregavam esta noção de uma percepção fugidia, de sutileza extrema que, muitas vezes, beira o imaterial.

A pesquisa desenvolvida parte do pressuposto de que a arte e o design configuram a percepção sensível no contemporâneo, e que a atualidade da poética duchampiana é um instrumental valoroso para se pensar o papel do design nas relações com o mundo projetado. Nosso cotidiano está imerso em imagens que circulam através de múltiplos artefatos de comunicação, e nossa percepção apreende novas configurações que desenham e designam outros mundos possíveis recriando nosso olhar e instituindo novos regimes de sensibilidade.

O artigo apresenta articulações entre a noção de inframince e projetos de design, cujos disparadores conversam, 
direta ou indiretamente, com as questões colocadas pelas operações infra-mince. São projetos que propiciam, ou traduzem, experiências sensíveis nas soluções projetuais propostas. Eles acompanham as reflexões extraídas do conjunto de sensações sutis, de percepções mínimas e de mudanças de sentido apreendidas na observação de estados das coisas e descritas por Duchamp nas notas sobre o inframince.

\section{O INFRAMINCE DE MARCEL DUCHAMP}

São muitos os adjetivos atribuídos à Marcel Duchamp, como: contraditório, paradoxal, irônico, complexo, desconcertante, transparente, misterioso, delirante, transgressor, ambíguo, lógico, e são tantos os livros, textos, artigos consagrados à sua obra que dimensionam sua importância e influência na atualidade, seja ela explícita ou não, em numerosos artistas contemporâneos. Duchamp foi um artista e um personagem múltiplo. Um pintor de ideias mais do que um pintor de pinturas - "nunca cedeu à falácia de conceber a pintura como uma arte manual e visual" (Paz, 2002 , p. 10). Foi um grande jogador de xadrez, venceu torneios e publicou uma obra sobre o xadrez que se tornou um clássico. Foi bibliotecário na biblioteca de SainteGeneviève tendo acesso as diversas obras clássicas sobre o problema da perspectiva. Organizou exposições de Brancusi nos Estados Unidos, deu aula de francês aos americanos de Paris, representou Adão nu na performance do Cine Sketch de Francis Picabia em 1924 (eternizada na foto de Man Ray), para falar somente de algumas facetas da figura singular que foi Duchamp.

No entanto, foi, sobretudo, o campo das artes plásticas que ele definitivamente embaralhou. Duchamp foi um dos representantes da irreverência dadaísta, não somente pelas proposições - os ready-made, o Grande Vidro, les objets 
trouvés, entre outras - mas pelo modo de conduzir sua vida. O movimento Dada deslocou a arte da produção de objetos para o "produzir-se" a partir de ações imprevistas, casuais, escandalosas, e mesmo absurdas. Usa a ironia e o nonsense para questionar as normas de valoração dos sistemas dominantes. O dadaísmo nasce dessa vontade de contestação de todos os valores vigentes, e, sobretudo, da vontade de contestação da própria arte (Argan, 1992). Segundo Anne Cauquelin (1992), é Duchamp quem estabelece uma distinção entre a esfera do artístico e do estético, quem libera o artista da figura romântica de gênio criador e coloca a arte em um sistema de signos, que circula no meio de outros signos e tem a linguagem como elemento fundamental para apreensão da obra (vide a importância dos títulos e jogos de linguagem na obra de Duchamp).

A noção de inframince ${ }^{1}$ pertence ao vasto campo de possibilidades que Duchamp insere na arte através dos seus deslocamentos de sentido, da ampliação da percepção que ultrapassa o olhar, da experimentação enquanto prática que equaliza o plano da obra ao plano da vida. Mas como falar sobre o inframince já que Duchamp não o define enquanto conceito? Para Franca-Huchet, "O Infra-mince é um enunciado de Marcel Duchamp sobre um conjunto de notas evocando aspectos sensoriais e envolvendo percepções da ordem do sensível, da sensação, da linguagem e da complexidade dos jogos de palavra" (2015, p. 41). Este conjunto de notas apresenta fragmentos de textos, diagramas, desenhos, com operações ou manifestações de fenômenos que se referem, segundo Olaio, "a entidades mínimas que surgem das relações entre as coisas ou são delas agentes" (1999, p. 138). A noção de inframince,

\footnotetext{
1 Palavra francesa que será mantida na língua original. A tradução da palavra inframince para língua portuguesa é a palavra infrafino, mas são poucos os autores que a utilizam. Em geral, mantém-se a palavra francesa e sem o uso do itálico. Nossa opção é a de manter a palavra francesa visto que é uma palavra criada por Duchamp, sem correspondente, de fato, em nenhuma outra língua.
} 
apesar de indicar uma dimensão mínima, infinitesimal, possui uma dimensão física e material, que não pode ser contida em uma existência puramente abstrata fruto de um pensamento estritamente racional. Nesse sentido, Duchamp apresenta o inframince como sendo uma descoberta (não uma invenção ou criação), são anotações apreendidas da observação de estados das coisas para proposições artísticas e reflexões estéticas a partir de um conjunto de sensações sutis.

As notas sobre o inframince, num total de 46, foram escritas entre os anos de 1935 e 1945 em papéis soltos, que foram encontrados em um pequeno pacote de notas manuscritas deixadas pelo artista em meio a vários papéis. Organizadas post mortem, foram publicadas pela primeira vez em 1980 com o título de Notes pelo Centro de Arte e Cultura Georges Pompidou. A publicação traz quase a totalidade dos escritos de Duchamp, sem acrescentar nenhum comentário ou explicação, e aparecem na seqüência em que os papéis estavam ordenados: Inframince, Le Grand Verre, Projets e Jeux de mots. Paul Matisse escreve, no Avant-propos do livro, estar convencido, assim como o próprio Duchamp, que explicações nunca explicam nada. No contexto da obra de Duchamps, a relevância dessa afirmação adquire maior valor e amplia o fator enigmático, irônico e complexo da obra e do artista.

A palavra francesa mince - fino, delgado, franzino, delicado, fraco, diminuto, escasso, medíocre, implica em definições que não são mensuráveis cientificamente. Articulada ao prefixo infra (do latim: abaixo de, posição inferior), Duchamp precisa a aparição de um fenômeno que está aquém de nossa percepção sensível e que não pode ser quantificado. A nota 5 contém a seguinte afirmação:

Nota 5 - inframince (adjetivo) não um nome - jamais fazer dele um substantivo 
olhos fixos fenômeno inframince

A palavra inframince é um adjetivo, um atributo, uma qualidade acrescentada àquilo que ela nomeia. Ela nunca deveria ser entendida como algo em si, mas o próprio Duchamp substantiva a palavra algumas vezes como, por exemplo: "Os infra minces são diáfanos e transparentes" (1999, p. 27). Longe de enfraquecer o termo, de desqualificar a lógica duchampiana, isso só demonstra que o contraditório pertence as práticas elaboradas por Duchamp, uma espécie de jogo (liberdade) que ele incute em suas próprias regras. Segundo Tomkins, em referência aos readymades, assumir suas próprias contradições fazia parte de "sua ambigüidade irônica, humorística e silenciosamente diabólica" (2013, p. 181).

Duchamp escreve a palavra inframince de três formas diferentes ao longo das notas (Fig. 1): inframince, infra mince e infra-mince. Entretanto, não há indícios nos textos que justifiquem as grafias diferentes, ou que orientem a lógica das escolhas. Franca-Huchet (2015) sugere que as diferentes grafias fazem parte do jogo de linguagem, do brincar com as formas e os sentidos assumidos pela palavra. Qual a apreensão do sentido de infra-mince com hífen? Franca-Huchet aponta para uma partição, um composto; infra mince separado poderia indicar a distensão do espaço e/ou do tempo; o inframince em uma única palavra conteria apreender o sentido em uma única visada. Independente das interpretações, Duchamp está sempre propondo aberturas, deslocamentos de sentido, para destruir traçados habituais. 
Figura 1: Página do livro Notes.

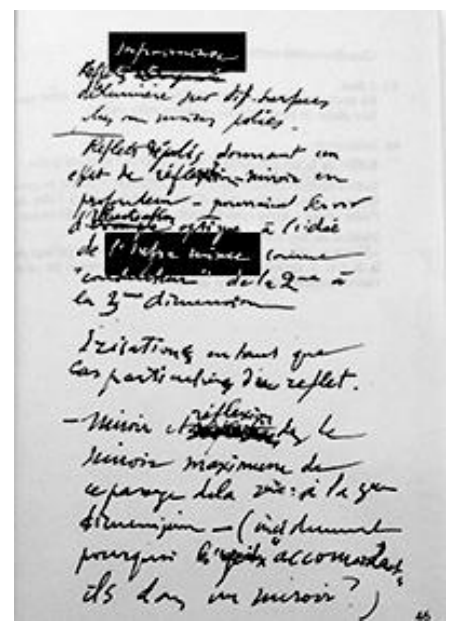

Fonte: Arquivo pessoal.

Por outro lado, considerando a grafia dos escritos, J. Suquet (1974) acredita que estas notações fazem parte do propósito de Duchamp para desorientar a própria linguagem. Nas palavras de Godinho, "Destruir a linguagem com frases bem caligrafadas, onde as palavras se (de)formam, ininteligíveis, com letras em falta [...] ou com decomposições e deformações que as desconectam e as fazem mudar de regime" (2011, p.68). O próprio Duchamp escreve nas notas sobre o Grande Vidro:

"simplificar a ortografia : suprimir as letras duplas. (contanto que não atrapalhe a pronuncia). chegar a um tipo de estenografia - evitando longos desenvolvimentos, explicação de uma palavra quando for necessário, mais sua equação estenográfica do que um discurso inflamado" (1999, p. 45).

Subverter a linguagem, usar o jogo de palavras (trocadilhos - Fig. 2), experimentar o som, o sentido, o "ser plástico da palavra (por nominalismo literal)" (Duchamp, 1999, p. 115), andar em várias direções, são artimanhas

\footnotetext{
2 Tradução nossa. Assim como de todas as traduções das notas de Marcel Duchamp.
} 
inventadas para sair das interpretações fáceis, para "pôr a nu" uma objetividade imbricada no plano da vida e da arte. Diferentemente de Franca-Huchet (2015), que sugere que as notas sobre o inframince são como um segredo a ser desvelado, Godinho (2011) insiste no caráter não interpretativo, na literalidade do delírio enquanto processo, em buscar uma aproximação "a bel-prazer" na multiplicidade da obra de um artista anômalo como Marcel Duchamp. Segundo a autora, a natureza do anômalo é o bordejar: "navegar mudando de rumo freqüentemente para apanhar vento favorável", é a de flutuar pelas bordas, experimentar para ver no que vai dar.

Figura 2: Anémic Cinéma, 1925-26 (com Man Ray e Marc Allégret). Detalhe: um dos discos que compõe o trabalho. Esquivons les ecchymoses des esquimaux aux mots exquis (evitemos os hematomas dos esquimós de palavras requintadas. Tradução nossa.)

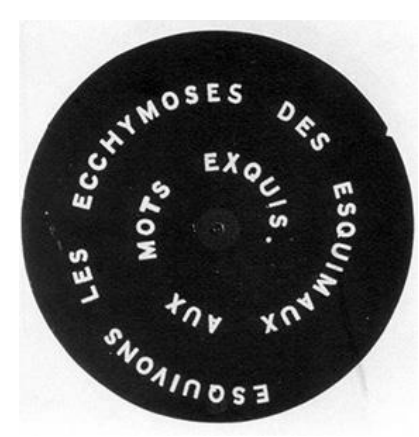

Fonte: http://telecinebrasil.blogspot.com.br/2012/03/anemiccinema-anemic-cinema-marcel.html

\subsection{UMA PERCEPÇÃO-PASSEIO}

Esse mudar as coordenadas constantemente, estar sempre saindo dos eixos, é o que propicia uma percepçãopasseio (Duchamp, 1978). Um estar em estado de vigília que vai passando de uma pequena percepção a outra, e assim sucessivamente. As operações inframince descrevem experiências da percepção sensível que buscam o aguçamento da percepção, sua perspicácia. Pode-se traçar 
um paralelo entre a noção de inframince e o campo das pequenas percepções articulado por José Gil (2005) a partir de Leibiniz, Deleuze e Fernando Pessoa.

Na verdade, a observação do campo das "pequenas percepções" ampliava os acontecimentos da maneira surpreendente: convertendo as micro em macropercepções como uma lente, a percepção do objeto modificava-se ao ponto de exigir uma descrição diferente. Da mesma forma que Fernando Pessoa aumentando a escala das "sensações mínimas", se dava os instrumentos necessários à análise e à elaboração da expressão poética, assim o pintor, o músico, o escultor trabalham constantemente com pequenas percepções (Gil, 2005, p. 11).

O processo perceptivo forma-se como um burburinho inconsciente. Ficamos aturdidos na fronteira que separa e sobrepõe o inconsciente e a consciência. Nossa percepção apresenta-se alucinatória, confusa, obscura, e é somente quando ela se torna relevante que tomamos consciência do que estamos percebendo e "o percebido assemelha-se a alguma coisa na qual ele nos força a pensar" (Deleuze, 1991, p. 143). As operações inframinces, descritas por Duchamp, também são fenômenos de limiar, são "entres", são sensações, mais ou menos delirantes, que convocam nossa atenção e nos fazem pensar.

Nota 4 - O calor de um assento (que acaba / de ser deixado) é infra-mince.

A atenção ao infinitamente pequeno, as insignificâncias cotidianas, é capaz de inventar outras formas de existir e de fazer arte. A sensação de calor é o indício residual de uma manifestação do inframince. O calor é a transferência de energia térmica de um sistema a outro, um trânsito disparado pela diferença de temperatura dos sistemas. O que pensar quando a atenção se volta para a energia térmica residual ocupada pela saída do corpo do assento? 
Qual o espaço que o calor ocupa? É possível medir o alcance dimensional do calor? Quanto tempo dura esse calor? Há alguma relação entre a duração temporal do sentar e a do calor residual resultante? Passo a imaginar as trocas térmicas do sentar e levantar de assentos em espaços públicos. Essas trocas poderiam sugerir alguma intimidade corporal? Quem será este outro que me ofertou seu calor ao acaso - acolho ou repudio? São muitas narrativas possíveis e imagináveis. Elucubrações delirantes disparadas por inframince.

Delirar é procedimento operatório para inventar. O mais interessante é pensar na literalidade do delírio proposto por Duchamp. É recorrente a afirmação da indiferença, do acaso, do distanciamento da emoção estética, dos juízos de valor no discurso de Duchamp. As notas são, em grande parte, uma espécie de manual de instrução, descrição de procedimentos, listas de coisas, que rejeitam "as necessidades expressivas até a neutralidade" (Godinho, 2011, p. 84).

Nota 11v (Nota 33 é semelhante) - Quando o fumo do tabaco também é sentido na boca de quem o exala, os dois odores casam-se por infra mince (infra mince olfativo).

$\begin{array}{rrr}\text { Nota } 21 \text { - sombra projetada } & \} & \text { infra mince } \\ \text { rasante } & \} & \\ \text { Impressão tipo foto } & \text { etc. } & \text { infra mince }\end{array}$

Nota 25 - O perolado, a seda moiré, iridescente : relação com o infra mince.

Nota 28 - Caricias infra mince

Nota $32 r$ - Lupa para o tocar (infra mince) $\mu \mu \mu \mu$ separando o infra mince transparentes

Os infra minces são diáfanos e por vezes

Nota 37 - Odores mais inframinces que cores

Essas operações inframinces engendram experienciar um conjunto de sensações "inéditas" ao enunciar mudanças de 
sentido nas relações com as coisas. A ênfase encontra-se na mudança da percepção que se tem dessas coisas, não nas coisas em si. Um mundo de sentidos ampliados para além da visão. É a dilatação da percepção que propicia a invenção de novas práticas e novas possibilidades materiais no mundo das coisas cotidianas. A percepção do calor do assento, nota 4, pôde ser materializada pelo desenvolvimento de tintas termocrômicas, que reagem a temperatura dos corpos, como observamos no projeto de design de superfície da designer Berzina Zane (Fig. 3).

Um projeto de papel de parede que reage ao calor do corpo deixando suas marcas impressas. Um registro da troca de energia térmica entre os sistemas: corpo e parede. São muitos desenhos possíveis. Desenhos que desaparecem quando o calor se vai. Para além de projetar um papel de parede, a designer projetou uma experiência sensível por operação inframince.

Figura 2: Touch me wallpaper, 2003. Designer: Berzina Zane.

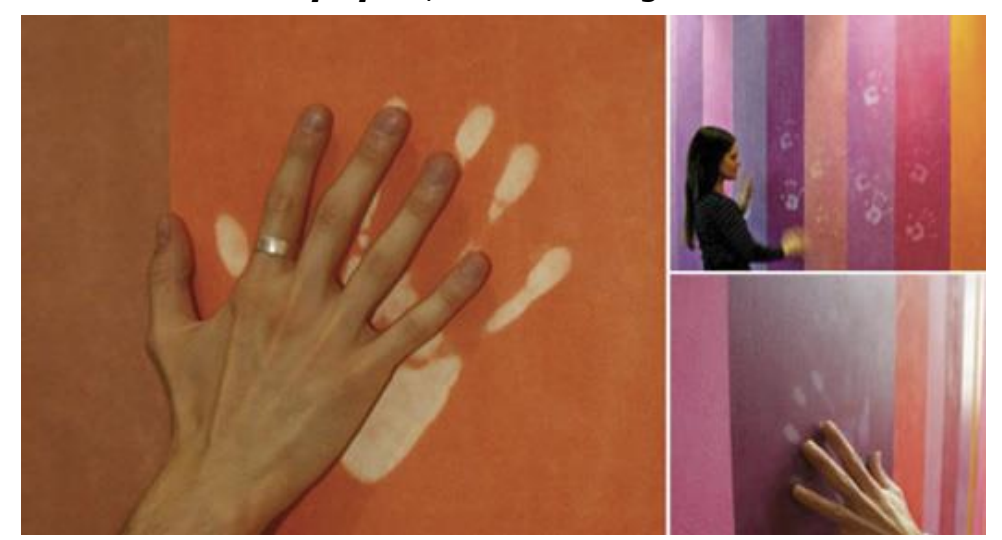

Fonte: http://www.zaneberzina.com.

\section{UM POSSÍVEL}

Nota 1 - O possível é um infra mince

A possibilidade de vários tubos de cores tornarem-se um Seurat é "a explicação" concreta do possível como infra mince. 
O possível implicando o devir - a passagem de um a outro tem lugar no infra mince

A primeira nota escrita por Duchamp afirmando ser o possível um inframince aponta para a abrangência do termo. É dizer que todo devir, todo vir a ser, comporta uma manifestação do inframince. Em termos filosóficos, o problema do possível, sendo o oposto do real, é um problema que se refere a própria existência. O possível "É um real fantasmático, latente. O possível é exatamente como o real: só lhe falta a existência" (Lévy, 2001, p. 16). Deleuze apresenta a seguinte questão: "Que diferença pode haver entre o existente e o não existente, se o não existente já é possível, recolhido no conceito, tendo todas as características que 0 conceito the confere como possibilidade?" (2006, p. 298). A resposta dada por Deleuze para esta questão está calcada na "diferença como o negativo determinado pelo conceito" (2006, p. 298). Algo como: um Seurat é uma pintura, uma realidade do objeto real quadro. A diferença entre um Seurat e os tubos de tinta colorida é os tubos não serem um quadro, não existirem enquanto quadro. Os tubos de tinta colorida são um possível, eles podem vir a ser uma pintura (sem deixar de ser tinta): um Seurat, um Matisse, um Picasso, um Rembrandt. São muitos os possíveis. Mas de tinta resultam pinturas, o que indica as limitações do possível oposto ao real que o condiciona.

Em termos filosóficos, Lévy (2011) afirma que um possível realizado não é uma criação, falta-lhe o fator inovação. O possível da tinta sempre será a realidade da pintura (quadro). A discussão colocada pela filosofia procura desconstruir o par virtual/real, que ganhou força com as tecnologias digitais e os sistemas informáticos, e considera o atual como sendo a realização (realidade) do virtual. O que se opõe ao virtual é o atual, não o real. O exemplo clássico 
dessa questão é a existência virtual da galinha no ovo. O ovo conhece a forma galinha, ele contém o complexo problemático do ser galinha. Na atualização do ovo há "invenção de uma forma a partir de uma configuração dinâmica de forças e finalidades" (Lévy, p. 16), há uma mutação de identidade. No devir galinha, não há vestígios do ovo.

Dessa forma, de que maneira podemos entender o possível inframince de Duchamp enquanto criação, invenção? Será que apontamos para direção certa? FrancaHuchet (2015) prioriza a questão do possível inframince pela pintura de Seurat, na sua concepção técnica científica, na transposição do inteligível (decomposição física da luz) em sensível (contemplação estética), na exploração tátil do visível, na dimensão poética da realidade e os futuros possíveis. Olaio (1999), também via Seurat, aponta para a invisibilidade da realidade objetiva acessada somente por suas manifestações residuais. Os pequenos pontos de tinta, entidades inframince, pressupõem a existência concreta de um invisível que tornará o visível possível. Falar do inframince é falar do sensível, de percepções de extrema pequenez, de sensações ínfimas que não podem ser contidas em uma existência puramente abstrata resultante de um pensamento estritamente racional. Então, como pensar o possível na literalidade delirante de Duchamp? Duchamp escreve:

\section{Possível}

A figuração é um possível (não como contrario do impossível nem como relativo ao provável nem como subordinado ao verossímil) O possível é unicamente um "mordente" físico [gênero vitríolo] que queima qualquer estética e calística. (1978, p. 88) 
Duchamp, na nota 46 , refere-se ao inframince como "condutor" (1999, p. 36), que efetua a passagem da $2^{a}$ para a $3^{a}$ dimensão e que tem no reflexo do espelho sua máxima. O inframince, no jogo da percepção sensível aguçada para o infinitamente pequeno, também é condutor do possível. Nas notas sobre o Grande Vidro (nota $83 \mathrm{v}$ ), há menção sobre a fisicalidade do possível, ou melhor, Duchamp fala de uma hipofisicalidade (1999, p. 51). As condições para o inframince são efetuadas por operações concretas determinadas: "corte, laminagem, prensagem, revestimento, secagem, camuflagem, lixagem, polimento, queimada, permeabilização, etc." (Godinho, 2011, p. 94). São experimentações por aproximação em materiais específicos escolhidos, cujo resultado não deve ser guardado.

Nota 26r - Espessura infra As infra-espessuras

(tipo "configuração" de clichês tipográficos)

Os infra-minces ( em uma única dimensão) ? ? os dois outros normais

A plaina instrumento grosseiro chegando apenas ao inframince / reentelamento (operação) podendo servir na exploração de infra minces

Modo: o estado ativo e não o resultado $\neg-$ o estado ativo não oferece nenhum interesse no resultado - o resultado sendo diferente se o mesmo estado ativo é repetido.

Modo: experiências - o resultado não deve ser guardado - nem apresentar algum interesse. não-comercial

Gruyère chumbado para dentições defeituosas

A criação/invenção não se encontra nos objetos, mas na banalidade da existência deles. E quanto maior a banalidade maior sua potência em ser. A lógica do inframince é uma lógica dos sentidos, que propõe mudar nossa percepção, fazer-nos reaprender a olhar, ou como afirmou Duchamp: o 
artista de amanhã para inventar o futuro será levado a "atravessar o espelho da retina como Alice in Wonderland para chegar a uma expressão mais profunda" (Godinho, 2011, p. 98). "Olhos fixos fenômeno inframince". Aguçar a atenção por meio da desaceleração, do isolamento, do intervalo, produzir uma transformação lenta e silenciosa mas extremante potente para recriar o vivido. Arriscamos dizer que o possível condutor de inframince não é equivalente ao possível filosófico apresentado anteriormente, aquele que se opõe ao real, pois sendo ele um condutor não podemos colocá-lo na extremidade de uma oposição - possível/real. Ele é percurso, trânsito, processo delirante, é o bordejar. Quando Lévy articula a arte ao conceito do virtual, ele afirma que:

A arte não consiste mais, aqui, em compor uma 'mensagem', mas em maquinar um dispositivo que permita à parte ainda muda da criatividade cósmica fazer ouvir seu próprio canto. Um novo tipo de artista aparece, que não conta mais história. É um arquiteto de espaço dos acontecimentos, um engenheiro de mundos para bilhões de histórias por vir. Ele esculpe o virtual (2001, p. 147).

A arte não consiste mais, aqui, em compor uma 'mensagem', mas em maquinar um dispositivo que permita à parte ainda muda da criatividade cósmica fazer ouvir seu próprio canto. Um novo tipo de artista aparece, que não conta mais história. É um arquiteto de espaço dos acontecimentos, um engenheiro de mundos para bilhões de histórias por vir. Ele esculpe o virtual. (2001, p. 147)

\subsection{PLANOS: CORTES E DOBRAS.}

A coleção 132.5 ISSEY MIYAKE (Fig. 4 e 5), nascida da relação entre algoritmos matemáticos e o fazer roupas, exemplifica as novas potências de criação resultantes de uma lógica inframince duchampiana (sem desconsiderar, 
obviamente, o avanço das tecnologias digitais). No outono de 2010, o Miyake Design Studio apresenta uma coleção desenvolvida em conjunto com o engenheiro têxtil Manabu Kikuchi, o engenheiro modular (pattern engineer) Sachico Yamamoto e uma equipe de designers, em que as roupas são geradas a partir de operações matemáticas, via ciência da computação, que criam uma infinidade de formas tridimensionais. De fato, são estudos de estruturas geométricas, cortes e dobras que se articulam entre os espaços bi e tridimensionais. Passagem do plano ao espaço e vice-versa. Estruturas modulares variáveis que se transformam em camisetas, vestidos, calças, saias, etc. Poéticas inframince do vestir.

Figura 4: Planificação roupa. "132 5. ISSEY MIYAKE", 2010.

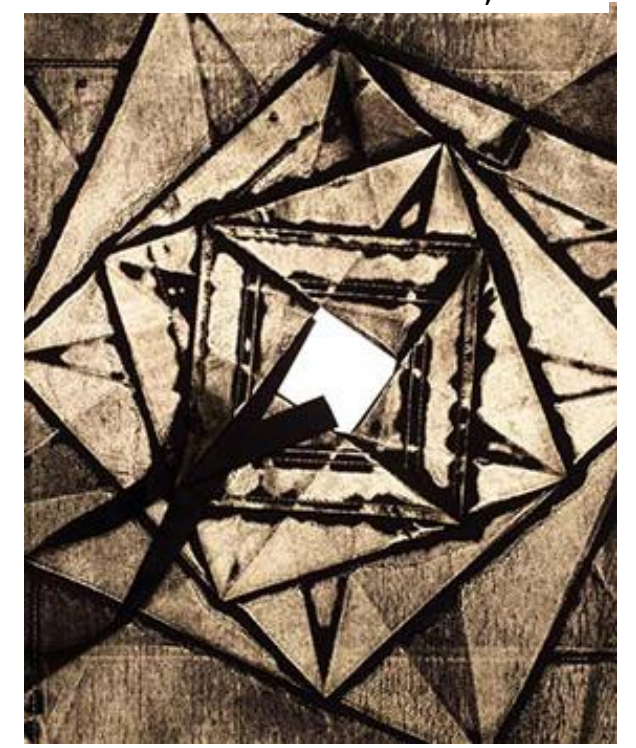

Fonte: http://www.isseymiyake.com/en/brands/132_5.html

Figura 5: "132 5. ISSEY MIYAKE", Designer: Issey Miyake.2010 


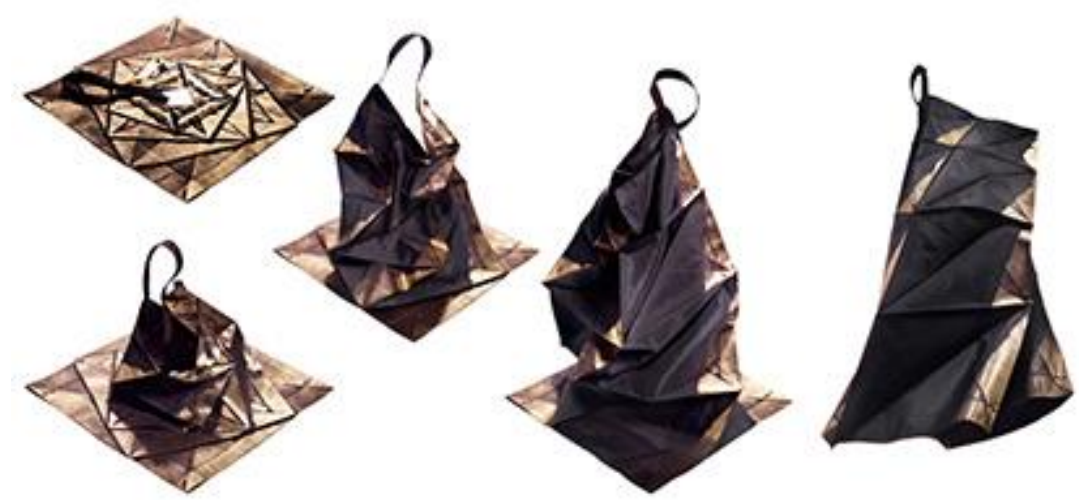

Fonte: http://www.isseymiyake.com/en/brands/132_5.html

Outro aspecto relevante para criação das peças de Issey Miyake é a escolha precisa dos materiais. As peças foram produzidas por uma mistura de fibras de poliéster (reciclagem química por pulverização de PET) e fibras de algodão, que fazem parte das pesquisas inovadoras sobre "regeneração e re-criação" implementadas pela equipe de Miyake. A literalidade do nome da coleção, "132 5. ISSEY MIYAKE", também chamou nossa atenção: 1 unidade de cada peça; 3 projeções tridimensionais (3D) de algoritmos matemáticos; 2 planificações geométricas bidimensionais (2D); espaço em branco seguido do 5 intervalo do desdobramento do plano-roupa em uma peça vestida pelo usuário, e o número 5 , considerado pela característica de versatilidade que a numerologia lhe atribui.

A coleção $\mathbf{1 3 2 . 5}$ ISSEY MIYAKE exemplifica um possível inframince "condutor" - passagem da $2^{\circ}$ para $3^{\circ}$ dimensão; passagem de algoritmos matemáticos para roupas.

\subsection{PROJEÇÕES NEGATIVAS}


Duchamp tinha grande interesse pelos aspectos precisos das ciências exatas, e procurava explorá-los na arte - com especial atenção para a matemática, ótica (estereoscopia) e os tratados de perspectiva, dos quais teve acesso quando foi bibliotecário. Nesse mesmo período, Duchamp já havia feito os primeiros ensaios e desenvolvia seus cálculos para a execução do Grande Vidro, ou A Noiva Despida por seus Celibatários, Mesmo (Cabanne, 1987, p. 68-69). Aqui é necessário também ressaltar o lado irônico, humorístico de Duchamp, na medida em que ele utiliza uma lógica própria no uso das ciências exatas enquanto disparador, gatilho de processos artísticos.

As engrenagens postas em marcha por Duchamp em $\mathbf{O}$ Grande Vidro dimensionam as maquinações engendradas para inventar figurações possíveis que estão para além das aparências, de uma pintura "que ultrapassa o espelho da retina". Tendo em vista que a aparência de um objeto de $n$ dimensões é a sua aparição num mundo de n-1 dimensões (Duchamp, 1978, p. 108), as imagens pintadas no vidro fazem referência as projeções negativas $(n-1)$ das figurações descritas, que podem ser compreendidas, unicamente, graças aos escritos contidos da Caixa Verde (1934) - uma espécie de bula para "ver" O Grande Vidro. Para esclarecer: imagens em 2 dimensões ( $n-1)$ são projeções negativas de imagens em 3 dimensões ( $n$ ). Nesse sentido, a noiva é representada em projeção negativa, em 4 dimensões $(n-1)$ de um virtual ( $n)$, de um modo virtual significado plasticamente.

Não cabe aqui uma análise dessa obra, mas vale atentar para as descrições precisas das maquinações de júbilo sobre a vida sexual imaginada pela noiva desejosa diante do fluxo de energia elétrica desnudante, do gás de iluminação que emana do espaço inferior do quadro (Duchamp, 1978 , p. 52-55; Gil, 2005, p. 65; Suquet, 1974). 
O delírio faz-se processo plástico, de máxima precisão para criar/inventar novos conjuntos de relações de elementos díspares. Linguagem e imagem estão entrelaçadas na produção de sentido da obra, mesmo se o sentido for um "anti-sentido" ou um nonsense.

\section{ENERGIAS DESPERDIÇADAS}

As operações inframince estão vinculadas as observações de gestos e fenômenos do dia a dia que, por vezes, são enunciados em frases soltas e apontam campos relacionais dos quais se pode observar vestígios, resíduos, ou ainda, energias desperdiçadas. Essas energias não passaram incólumes por Duchamp, ao contrário, ele elabora práticas que transformam essas pequenas energias em acontecimentos.

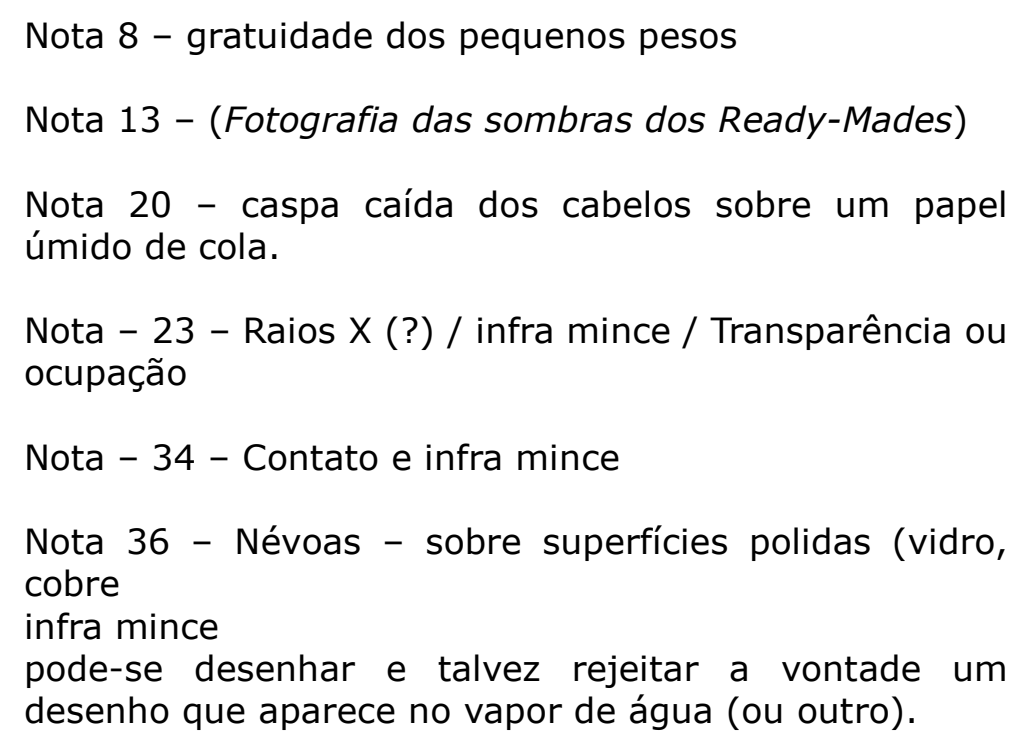

A valorização dos restos, das sobras, atentar para os vestígios do tempo é bem exemplificado na obra Criação de Pó, de 1920. A pedido de Duchamp, Man Ray fotografa bolas de poeira acumuladas na superfície do Grande Vidro (Naumann, 1999, p. 83). Aqui há muitas questões envolvidas por causa do uso da fotografia enquanto obra, 
que se encontrava em plena expansão na época. De fato, no caso de Duchamp, a "obra" fotográfica transforma-se em registro do acontecimento/obra - indício manifesto dos resíduos de um ato. Isso gerou uma aproximação entre a fotografia e o ready-made, que Dubois vai explicitar como "a lógica do índice, do ato e do traço, do signo fisicamente ligado a seu referente antes de ser mimético" (1998, p. 257). Vale ressaltar o que Godinho afirma, em referência aos ready-mades, que a passagem de um objeto qualquer (indiferença) para devir um ready-made (diferença), acontece com "máxima precisão" quando as pequenas energias, forças necessárias de transformação, não ocupam mais o espaço-tempo habituais (2011, p. 89). Assim as bolas de poeira são, simultaneamente, traços do tempo e do espaço ocupado por uma matéria física, habitualmente sem importância, indiferente ao olhar do "gosto", que se transformam em diferença na imagem fotográfica da superfície instigante produzida pelo jogo de luzes e sombras. A lógica do ato, pertence tanto ao ato fotográfico de Man Ray quanto ao acontecimento poeira percebido e transformado por Duchamp.

Essas pequenas energias desperdiçadas, seja pelo excesso ou pela simples perda, são registradas, colecionadas e transformadas (ou transmutadas), transferidas entre corpos criam campos de força que também passam da indiferença à diferença. São energias intensivas, por vezes inópticas e imperceptíveis como: "O excesso de pressão sobre um botão elétrico, a exalação da fumaça do tabaco, o crescimento das unhas e dos cabelos, o cair da urina e da merda, movimentos impulsivos do medo,[...] o ronco, os desmaios ..." (Duchamp, 1999, p. 108).

\subsection{FIGURAS SONORAS}


No campo do design, o projeto para criação da identidade visual da orquestra Camerata de Lausannea, do designer Demiam Conrad, que explora experimentos acústicos sobre o efeito do som na matéria física, apresentase como uma forma de repensar as figuras sonoras (Fig. 6) pesquisadas por Ernst Chlandi, na década de em 1780.

Ernst Chladni, em seus experimentos, usa uma placa metálica rígida coberta por uma fina camada de areia, na qual passa um arco de violino pela borda que a faz vibrar. Dependendo da frequência e intensidade da vibração e das regiões onde vibram, os grãos de areia deslocam-se criando padrões variados. São chamados de nodos as regiões em que não há vibração alguma, onde se acumulam os grãos. Nas regiões de vibrações fortes os grãos são expulsos criando os vazios das figuras. São as variações de frequência que produzem as chamadas "figuras sonoras de Chladni". Quanto mais elevadas as frequências maior a complexidade das formas produzidas.

Figura 6: Ernst Chladni: físico alemão considerado o pai da acústica moderna.

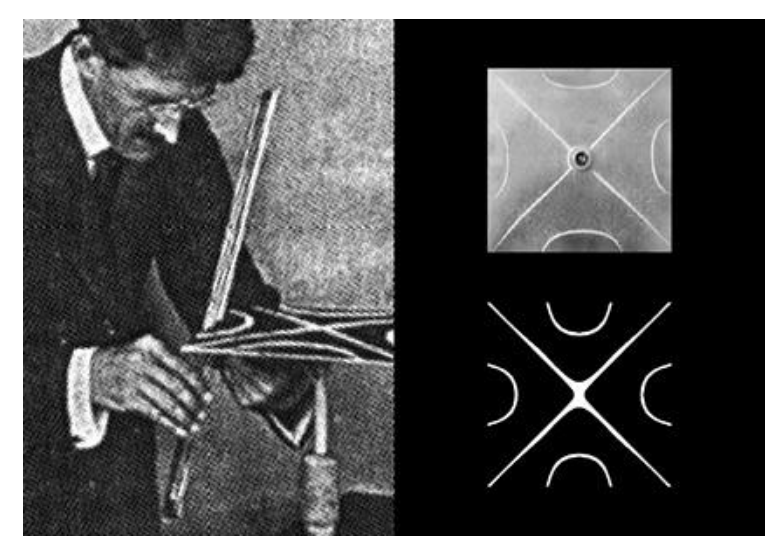

Fonte:

http://www.amenidadesdodesign.com.br/2014/07/tor nando-padroes-de-som-visiveis.html

Para a criação da identidade visual da Camerata de Lausannea, o designer Demiam Conrad seguiu a linha geométrica descoberta por Chladni. Buscando uma representação mais contemporânea, e mais controlável nos 
resultados, Conrad usou um software escrito por Mathieu Rudaz o que permitiu gerar imagens diretamente no computador a partir de frequências determinadas. O projeto também contou com uma fonte modernista (Neutraface) e com a colaboração do tipógrafo Emmanuel Rey para equilibrar a sutil geometria do logotipo (Fig. 7).

A energia produzida pela vibração que se torna imagem. Campo de força sonoro, pequenas energias desperdiçadas colecionadas e transformadas (ou transmutadas), transferidas entre corpos criam campos de força que também passam da indiferença à diferença. Devir identidade visual dinâmica, em constante transformação e "musicadas" pelos variados programas executados pela orquestra.

Figura 7: Exemplo de programas da Camerata de Lausannea. Designer: Damian Conrad.

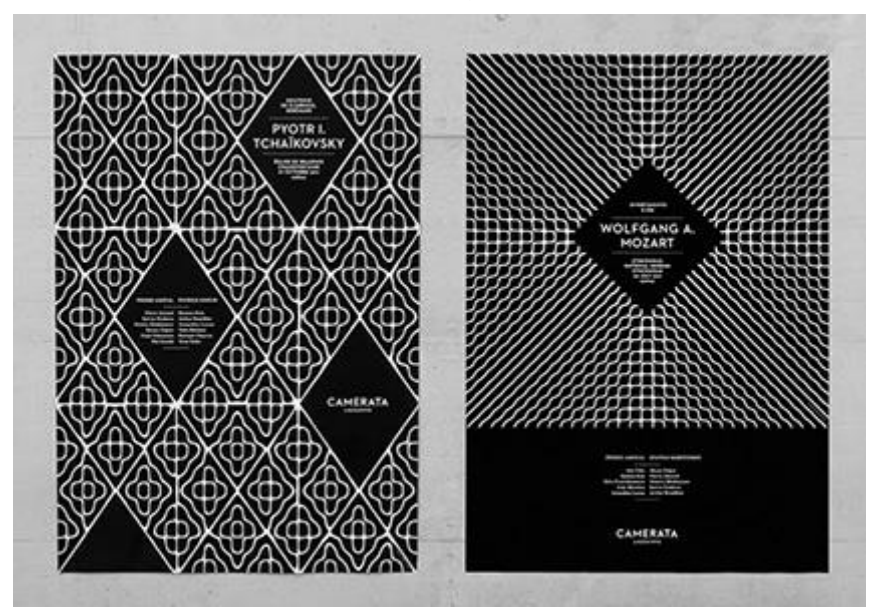

Fonte:

http://www.amenidadesdodesign.com.br/2014/07/tornando -padroes-de-som-visiveis.html

\section{ENTRE O EU E O MIM (JE ET MOI)}

O início da conversa (entre o eu e o eu) merece uma citação de Duchamp. Pouco antes de completar oitenta anos, em 1966, Duchamp concede uma longa entrevista para 
Pierre Cabanne, que Ihe pergunta de pronto qual teria sido sua maior satisfação na vida. Eis a resposta de Duchamp:

Primeiro ter tido sorte. Porque, na verdade, nunca
trabalhei para sobreviver. Considero trabalhar para
sobreviver um pouco imbecil do ponto de vista
econômico. Espero que algum dia possamos viver sem
sermos obrigados a trabalhar. Graças a minha sorte,
passei pela vida sem me molhar. Compreendi, em dado
momento, que não precisava embaraçar a vida com
tanto peso, tantas coisas para fazer, tais como esposa,
filhos, uma casa de campo, um automóvel. E eu
entendi tudo isso, felizmente, bem cedo. [...] Também
não conheci o esforço para produzir; a pintura não foi
um escape para mim, ou um desejo imperioso de me
exprimir. Nunca tive este tipo de necessidade de
desenhar pela manhã, à tarde, o tempo todo, fazer
croquis etc. Não posso dizer mais nada. Não tenho
remorsos(1987, p. 23).

Duchamp, em diversos momentos, fala de um distanciamento necessário para suas escolhas artísticas: do gosto, das emoções, da expressão do gesto, das convenções pictóricas, produzindo uma distância entre o je e o moi. Nas palavras do artista "Minha intenção sempre foi a de fugir de mim, embora soubesse perfeitamente que eu estava me usando. Chame isso de um jogo entre o 'eu' e o 'mim'" (Tomkins, 2013, p.181). Um movimento de negação. Mas o que isso significa? Como pensar a relevância das contradições que se afirmam constantemente nas pequenas diferenças?

As notas trazem várias passagens sobre "separação infra-mince", "intervalos", "lacunas", "isolamentos", que remetem a uma distância, ou um afastamento:

Nota 6 - A alegoria (geralmente) é uma aplicação do infra-mince

Nota 7 - Similitude / similaridade

O mesmo (fabricado em série)

aproximação prática da similaridade

No tempo um mesmo objeto não é o mesmo em 1 segundo de intervalo 
Qual relação com o princípio de identidade?

Nota 18 - A diferença (dimensional) entre 2 objetos feitos em série [saídos do mesmo molde] é um infra mince quando o máximo (?) de precisão é obtido.

Como entender esse jogo, que instaura o tempo, a produção em série dos objetos fabricados, a alegoria - esse dizer uma coisa para fazer entender outra? Maquinações de um existir imanente, de um Duchamp que alegoriza a si mesmo (como podemos perceber em sua resposta a Cabanne). Ele não nos esclarece com seu texto, ao contrário, ele amplia os delírios e os possíveis. Por isso nos permitimos aprofundar nossas "invenções" narrativas inspiradas em suas notas sobre o infra-mince. Vamos lá.

Na filosofia, é Kant, no final do século XVIII, quem introduz a distinção entre uma consciência empírica e uma consciência transcendental, ou segundo Deleuze(1997), um Eu [Je] e um Eu [Moi]. Um Eu [Moi] que não para de mudar, receptivo, que se dá no tempo, e um Eu [Je] que é ato, e determina ativamente minha existência. Mas, "eu, considerado como sujeito pensante, me conheço como objeto pensado dado a mim mesmo na intuição do mesmo modo que conheço os outros fenômenos, isto é, não como sou, mas como me apareço"3 (Machado, 2009, p.112). Essa consciência que não se encontra mais localizada em uma alma divina, mas que resulta do entendimento entre o Je e o Moi, produz um sujeito que se modula na relação consigo mesmo. Ou seja,

[...] o Eu não é um conceito, mas a representação que acompanha todo conceito; e o Eu não é um objeto, mas aquilo que a todos os objetos se reportam como à variação contínua de seus próprios estados sucessivos e a modulação infinita de seus graus no instante. A

\footnotetext{
${ }^{3}$ Os pronomes pessoais da 1o pessoa do singular Je e Moi, da língua francesa, que correspondem aos diferentes Eus, assumiram formas distintas de acordo com a tradução para língua portuguesa de diferentes autores. Por exemplo, Roberto Machado manteve os pronomes na língua francesa, enquanto Peter Pál Pelbart preferiu dar um tratamento gráfico diferenciado para a palavra Eu - usando o Eu em itálico para falar do eu transcendental, e o Eu em fonte regular para designar o eu empírico.
} 
relação conceito-objeto subsiste em Kant, mas encontra-se duplicada pela relação $E u$-Eu, que constitui uma modulação, não mais uma moldagem. (Deleuze, 1997, p. 39-40)

Tem-se um Moi mutável, cambiante no tempo, um sujeito fenomênico que é afetado pelo Je, o eu transcendental que o determina. Para Deleuze, o intervalo que se encontra entre um e outro não constrói nenhuma identidade - mesmo que a unidade seja mantida, ao contrário, provoca fissuras que fazem com que o Moi apreenda o Je como um Outro nele. Ou ainda, "o 'eu penso' afeta o tempo e só determina a existência de um eu que muda no tempo e apresenta a cada instante um grau de consciência" (Deleuze, 1997, p. 38).

Uma ligação direta, uma violação do tipo roubar um carro, pode ser estabelecida entre o intervalo Inframince, ou a lacuna (écart) - o espaço "vazio", real ou imaginário, que se dá na transposição de um em outro, na modulação do Eu$E U$. A fissura, que faz com que o Moi apreenda o Je como um Outro nele, é um infra-mince.

As apropriações sugeridas pela modulação eu/eu (sujeito/objeto) vale, também, quando se considera o objeto, não enquanto uma matéria inerte passiva, mas na qualidade de um artefato relacional que modula modos de subjetivação no sujeito social. A atenção especial dada aos objetos fabricados em série é parte integrante da poética dos ready-mades (Olaio, 1999, p. 142). As reflexões de Duchamp ultrapassam a mera lógica do consumismo capitalista para focar nas pequenas diferenças que instauram as manifestações identitárias, que são extremamente frágeis e efêmeras. Um complexo jogo entre o eu e o mim.

\subsection{OBJETOS ORDINÁRIOS}


O $5 \bullet 5$ estúdio é um coletivo francês de design que busca questionar, sistematicamente, suas ações (e negócios) e seus próprios processos de criação, buscando valorizar a ética e a responsabilidade social em sua atuação profissional. Tendo desenvolvido inúmeros projetos, em grande ou pequena escala, para o mercado de luxo ou produtos de consumo de massa, participado de diversas exposições ao redor do mundo, o $5 \bullet 5$ inova nas abordagens sem esquecer o compromisso de projetar para todos, enfrentando os desafios do design contemporâneo.

Um dos primeiros projetos produzidos pelo coletivo foi o projeto Objetos ordinários, de 2004. Os castiçais 3000 (Fig. 8) fazem parte desse projeto, que tinha por objetivo restaurar o "ego" de objetos anônimos, que pertencem ao cotidiano das pessoas. Objetos banais que todos conhecem, embora não os valorizem. São escondidos nas gavetas em dias de festa, mas atravessaram o tempo e as revoluções técnicas, mesmo sem terem obtido um grande reconhecimento. O projeto propõe releituras destes objetos ordinários para lhes dar integridade e respeito. Pode-se observar que a questão na está calcada no redesenho do objeto. Em dar uma nova forma para sua antiga função. $O$ projeto reorganiza, acopla e agrega novos sentidos aos já existentes. Transforma a indiferença em diferença. Transmuta benjamin (adaptador) em castiçal em uma operação infra-mince de passagem de um ao outro. 0 projeto Objetos ordinários joga o jogo complexo das identidades frágeis e efêmeras.

Figura 8: Castiçal 3000. Objetos ordinários, 2004. Design: Coletivo $5 \bullet 5$ Design Studio 


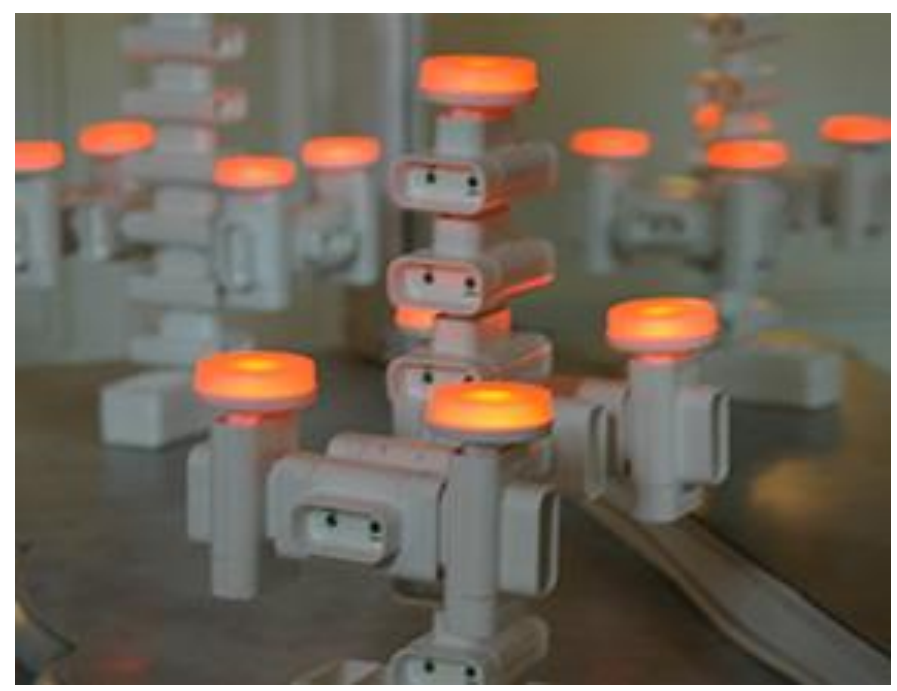

Fonte: http://www.5-5designstudio.com/

Duchamp entende a criação como reorganização de elementos para se produzir novos sentidos, novas formulações que escapam ao gosto, ao já reconhecido e habitual. E é na banalidade das coisas que se encontra o potencial do vir a ser.

\section{6. É O OBSERVADOR QUEM FAZ O QUADRO}

Há na poética do pensamento duchampiano a introdução de um fator muito importante para qualquer reflexão que se possa fazer sobre a obra desse artista. Em uma palestra sobre o processo criativo, realizada em 1957, Houston/Texas, durante a Conferência da Federação Americana de Artes, Duchamp explana sobre o papel mediúnico do artista. Ou melhor, ele questiona as implicações do artista enquanto gênio criador, e o real controle sobre sua própria produção artística. Por controle entende-se o grau de consciência que o artista tem do alcance da sua obra. Ao refletir sobre inúmeros artista existentes, Duchamp infere que somente alguns são aceitos e discutidos pelo público, e poucos, muito poucos, são consagrados e fazem parte dos "manuais" da história da arte. O que pensa Duchamp a partir dessa reflexão? 
O papel da consciência no ato criativo, segundo Duchamp, apresenta-se como um "coeficiente artístico" da obra (Tomkins, 2013, p. 518). O que isso significa? Há dois pólos na criação da arte: o artista e o espectador. O "coeficiente artístico" pessoal contido na obra é uma espécie de média aritmética (uma diferença) entre a intenção do artista e a apreensão do espectador. É uma lacuna resultante da luta travada na realização do trabalho decisões, sofrimentos, satisfações, recusas - naquilo que o artista pretendia passar com sua obra mas não conseguiu. Por outro lado, o espectador põe a obra na roda ao decifrar, interpretar as particularidades, contribuindo diretamente com o ato criativo, inclusive, percebendo atributos que não haviam sido pretendidos pelo artista. Nesse sentido, o artista não tem total consciência de sua realização. A posteridade, ao lado do espectador, é que consagra o artista e dá valor social as suas declarações. Importante ressaltar que, para Duchamp, a arte, assim como a emoção, pode ser ruim, boa, ou mesmo indiferente, sem deixar de ser arte. Não é sua classificação na escala estética que a define, embora seja essa classificação que determina sua posteridade.

Por isso a proposição "é o observador quem faz o quadro" é tão significativa para as proposições artísticas de Duchamp, e alinha-se ao que Marshall McLuhan vai afirmar cinquenta anos mais tarde: $\mathbf{O}$ meio é a mensagem; ou com a lei cibernética, retomada pelas teorias da comunicação, que diz: o observador faz parte do sistema que ele observa; observando ele produz as condições de sua observação e transforma o objeto observado, "observa" Cauquelin (1992).

Considerar o espectador parte do ato de criação é, radicalmente, transformador do próprio conceito de arte. Duchamp estabelece uma distinção entre a esfera do artístico e do estético, é quem libera o artista da figura 
romântica de gênio criador e coloca a arte em um sistema de signos, que circula no meio de outros signos e tem a linguagem como elemento fundamental para apreensão da obra. Linguagem no amplo sentido. Segundo Duve (2009), dizer "isto é belo" ou "isto é arte", significa estarmos falando de assuntos absolutamente distintos. Pode-se dizer que uma pá de neve é bela, mas dizer que uma pá de neve é arte, é uma outra história, afirma o autor.

Os deslocamentos de sentido que Duchamp produziu com sua obra e vida também alcançou o design, que deixa de buscar a melhor forma (mais bela) para desempenhar uma função específica, característica do período moderno, para projetar as relações entre produto, usuário e ambiente. Segundo Manzini (2008), o design desloca o olhar da produção de objetos para as ações propostas por eles. Algo como: em vez de projetar o objeto fogão, projeta-se a partir do cozinhar. Uma mudança de sentido das ações projetuais. Uma mudança nos modos de ver e ser no mundo.

O projeto de Marjin van der Poll é exemplar no quesito: o observador quem faz a obra (Fig. 9). Projeto de uma poltrona que se configura a partir da ação do usuário (espectador).

Figura 9: Do hit Chair 2000. Designer: Marijn van der Poll. 


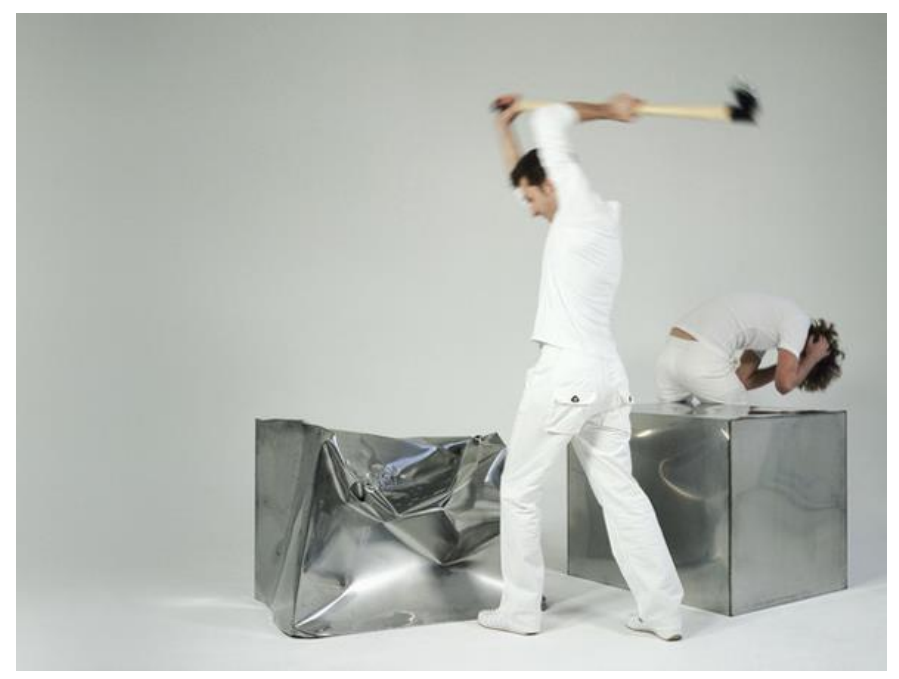

Fonte: http://www.droog.com/webshop/furniture/do-hit-chair--hit-by-van-der-poll/

\section{CONCLUSÃO}

O artigo apresentado resulta de parte de uma pesquisa sobre as relações entre o campo ampliado do design e as configurações sensíveis projetadas ${ }^{4}$. O viés que conduz o artigo é a noção de inframince legada por Duchamp em suas notas manuscritas. O intuito era aprofundar a noção de inframince e seu potencial relacional, além de buscar projetos de design que continham qualidades experienciáveis da percepção sensível para exemplificar as questões.

O pano de fundo da pesquisa é o entendimento do design e da arte enquanto campos de atuação híbridos entre criação social, econômica, cultural e subjetiva, portanto não produzem somente novas coisas, mas novas formas de existir. Florescem na transversalidade de suas conexões com áreas de conhecimento distintas. Dessa forma, a pesquisa circulou por pensamentos diversos, sempre mantendo o viés dos fenômenos oriundos das pequenas percepções, do

\footnotetext{
${ }^{4}$ Pesquisa desenvolvida no Programa de Morumbi com bolsa do PROGRAMA NACIONAL DE PÓS-DOUTORADO (PNPD/CAPES). Título da pesquisa: Sobre o infinitamente pequeno e as sensações das coisas mínimas: design e arte nas novas configurações do sensível.
} 
infinitamente pequeno, das sensações das coisas mínimas fenômenos inframince.

Os projetos apresentados são uma ínfima amostra de muitos outros projetos pesquisados, mas são representativos de um design que tem o sensível enquanto disparador do projeto. Com maior ou menor grau de complexidade, os projetos carregam novas formas de afetividade, e ampliam o campo de pesquisa das aproximações entre arte e design em seus mais variados encontros.

Uma das questões emergentes na pesquisa é a consolidação das interseções processuais, dos processos criativos que impulsionam tanto a arte quanto o design. Enfim, é uma pesquisa que não se esgota neste artigo, e que abre outros possíveis, outras conexões para o pensamento.

\section{REFERÊNCIAS}

ARGAN, Gian Carlo. Arte Moderna. São Paulo: Companhia das Letras, 1992.

CABANNE, Pierre. Marcel Duchamp: engenheiro do tempo perdido. São Paulo: Editora Perspectiva, 1987.

CAUQUELIN, Anne. L'art contemporain. Paris: Presses Universitaires de France, 1992.

DELEUZE, Gilles. A dobra: Leibniz e o barroco. Campinas: Papirus, 1991.

DELEUZE, Gilles. Crítica e clínica. São Paulo: Editora 34, 1997.

DELEUZE, Gilles. Diferença e repetição. Rio de Janeiro: Graal, 2006.

DUBOIS, Philippe. $\mathbf{O}$ ato fotografico. Campinas: Papirus, 1998.

DUCHAMP, Marcel. Notes. Paris: Flammarion, 1999. 
DUCHAMP, Marcel. Escritos. Duchamp du signe. Barcelona: Gustave Gile, 1978.

DUVE, Thierry de. Cinco reflexões sobre o julgamento estético. Dossiê.

REVISTA PORTO ARTE. PORTO Alegre: V. 16, № 27, nov. 2009. Disponível em:

http://www.seer.ufrgs.br/PortoArte/article/viewFile/18187/1 0698. Acesso em 09/05/2016.

FRANCA-HUCHET, Patrícia. Infra-mince ou um murmúrio secreto. Art Research Journal. ARJ. Brasil: V. 2, n. 2 , p. 40-59, jul. / dez. 2015. Disponível em:

http://www.periodicos.ufrn.br/artresearchjournal/article/dow nload/7297/5737. Acesso em 20/03/2014.

GIL, José. A imagem nua e as pequenas percepções. $2 a$ edição. Lisboa: Relógio D'Água, 2005.

GIL, José; GODINHO, Ana. O humor e a lógica dos objetos de Duchamp. Lisboa: Relógio D’Água, 2011.

LÉVY, Pierre. O que é o virtual. Rio de Janeiro: Editora 34, 2001.

MACHADO, Roberto. Deleuze, a arte e a filosofia. Rio de Janeiro: Jorge Zahar Editora, 2009.

MANZINI, Ezio. Design para inovação social e sustentabilidade: comunidades criativas, organizações colaborativas e novas redes projetuais. Rio de Janeiro: Epapers, 2008.

MINK, Janis. Duchamp: arte como contra arte. Colônia: Taschen, 2000.

NAUMANN, Francis. Marcel Duchamp: The art of making art in the age of mechanical reproduction. Nova Iorque: Abrams, 1999.

OLAIO, António. O campo da arte segundo Marcel Duchamp. Tese (Doutorado em arquitetura). Departamento de Arquitetura da Faculdade de Ciências e Tecnologia da Universidade de Coimbra. Coimbra, 1999. Disponível em: https://eg.sib.uc.pt/handle/10316/3749. Acesso em 10/08/2013. 
PAZ, Otávio. Marcel Duchamp ou o castelo da pureza. São Paulo: Editora Perspectiva, 2002.

SUQUET, Jean. Le Miroir de la Mariée. Paris: Flammarion, 1974 (p. 21).

TOMKINS, Calvin. Duchamp: uma biografia. São Paulo: Cosac\&Naify, 2013. 